\title{
A RARE CASE REPORT OF FOETUS IN FOETU
}

\section{Rajiv Kumar', Chandan Kumar², Subhrajit Hazra33, Sudhanshu Shekar', Israrul Haque 5}

${ }^{1}$ Associate Professor, Department of Radiodiagnosis, PMCH, Patna.

${ }^{2} 3^{\text {rd }}$ Year Junior Resident, Department of Radiodiagnosis, PMCH, Patna.

$32^{\text {nd }}$ Year Junior Resident, Department of Radiodiagnosis, PMCH, Patna.

4Junior Resident, Department of Radiodiagnosis, PMCH, Patna.

5Junior Resident, Department of Medicine, PMCH, Patna.

\section{ABSTRACT}

Foetus in foetu is a rare congenital anomaly due to abnormal embryogenesis of monozygotic twin (specially diamniotic, monochorionic pregnancy) in which parasitic twin is located within the body of twin in the vertebrate foetus.(1) The patient present with an abdominal mass during infancy or childhood. The ultrasonography, computed tomography, and multiplanar MRI scan revealed a mass in which the contents favour the presence of a large retroperitoneal foetus in foetu with significant mass effect of the adjacent structures and it is not a tumour.

\section{KEYWORDS}

Foetus, Twin, Teratoma, Parasitism, Abdomen, Bone, Diamniotic Monochorionic, Retroperitoneal.

HOW TO CITE THIS ARTICLE: Kumar R, Kumar C, Hazra S, et al. A rare case report of foetus in foetu. J. Evolution Med. Dent. Sci. 2016;5(70):5137-5141, DOI: 10.14260/jemds/2016/1165

\section{INTRODUCTION}

It is a rare condition, only few case reports are available. There are multiple theory, but the most acceptable theory is foetal parasitism. We have to differentiate this from the teratoma, which have malignant potential versus foetus in foetu, which is completely benign.(2) The lesion has to be removed because it can cause obstruction. This condition has a 2:1 male predominance with most patients presenting with an abdominal mass in the 1st year of life. Other reported locations include the cranial cavity and the scrotum. $(3,4)$ The number of foetuses in foetu is usually single; however, multiple foetuses in foetu have been reported.(5) The intent of this case report is to describe the characteristic USG, computed tomographic (CT), and MRI findings of this unusual entity.

\section{CASE REPORT}

Foetus in foetu is a condition in which malformed and parasitic foetus is located in the body of it twin. The anomaly was first defined in early nineteenth century by Meckel is a rare congenital anomaly.(6) The lesion is predominantly retroperitoneal in $80 \%$ of cases.(7) The term foetus in foetu quoted by Willis.[7]

A one-year-old female child comes in the Department of Paediatric Surgery in PMCH with abdominal mass in the right flank. At physical examination, the mass was firm, smooth, and nontender. Laboratory test findings were unremarkable. The paediatric surgeon send the child to our Department of Radiology, PMCH.

Financial or Other, Competing Interest: None.

Submission 27-06-2016, Peer Review 25-07-2016,

Acceptance 01-08-2016, Published 01-09-2016.

Corresponding Author:

Dr. Chandan Kumar,

$3^{\text {rd }}$ Year Junior Resident,

Department of Radiodiagnosis,

$\mathrm{PMCH}$,

Patna.

E-mail: cks2k7@gmail.com

DOI: $10.14260 /$ jemds $/ 2016 / 1165$

\section{We have done the USG, the key USG images are}

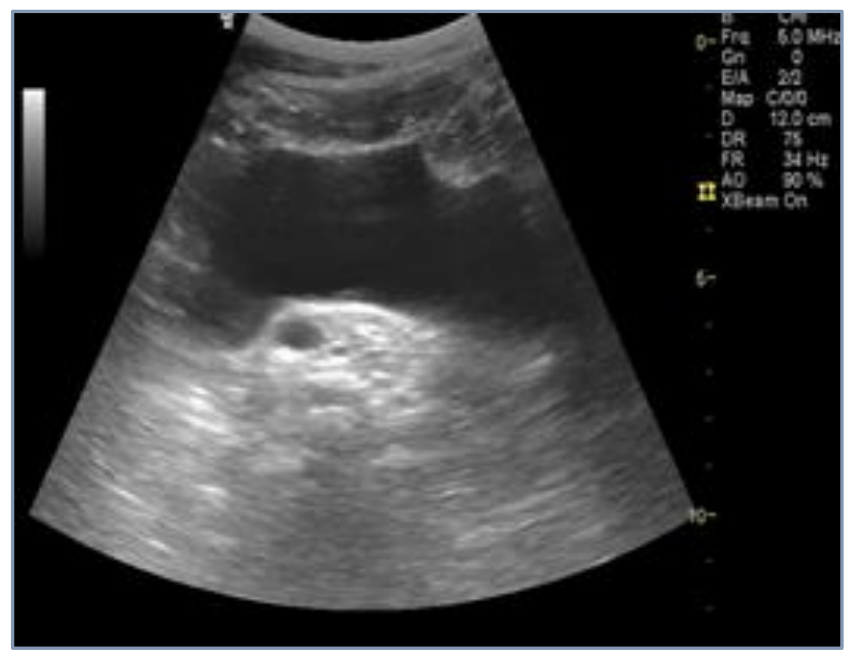

Fig.1

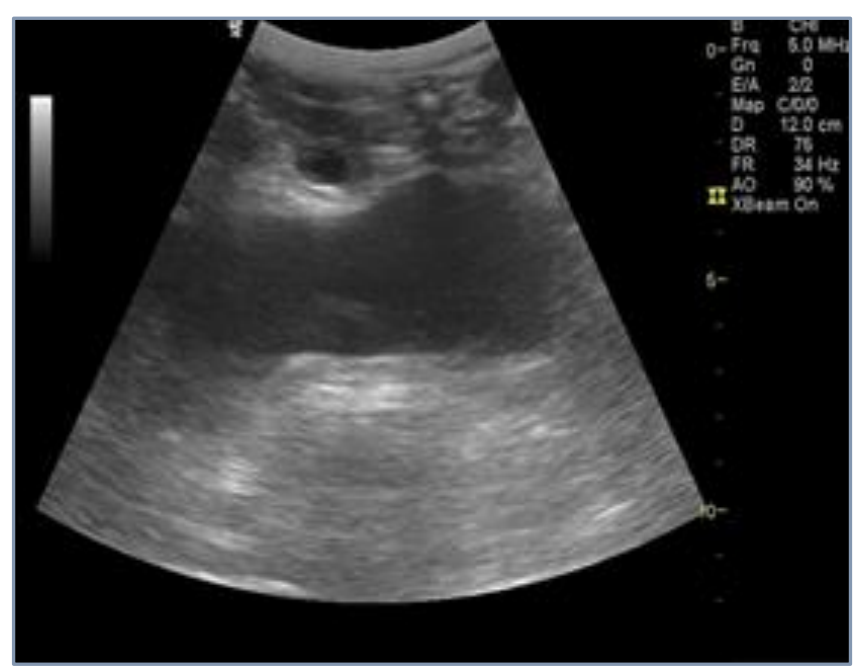

Fig.2 


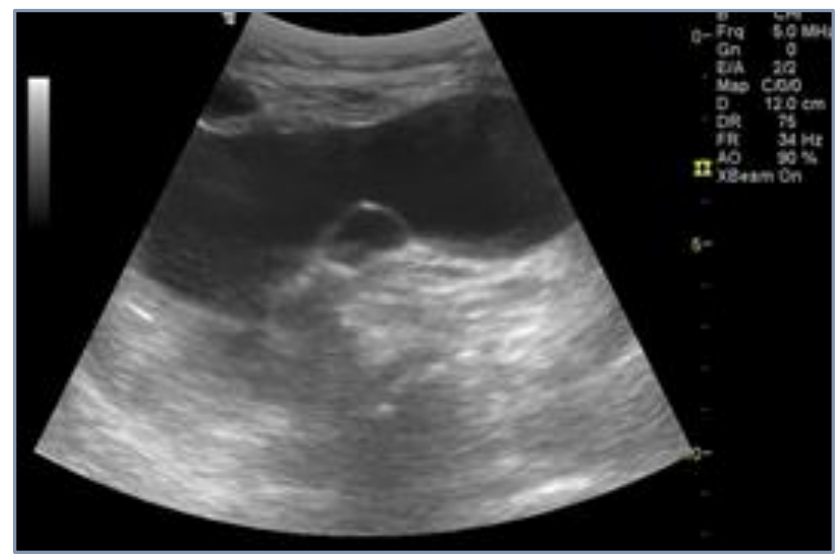

Fig.3

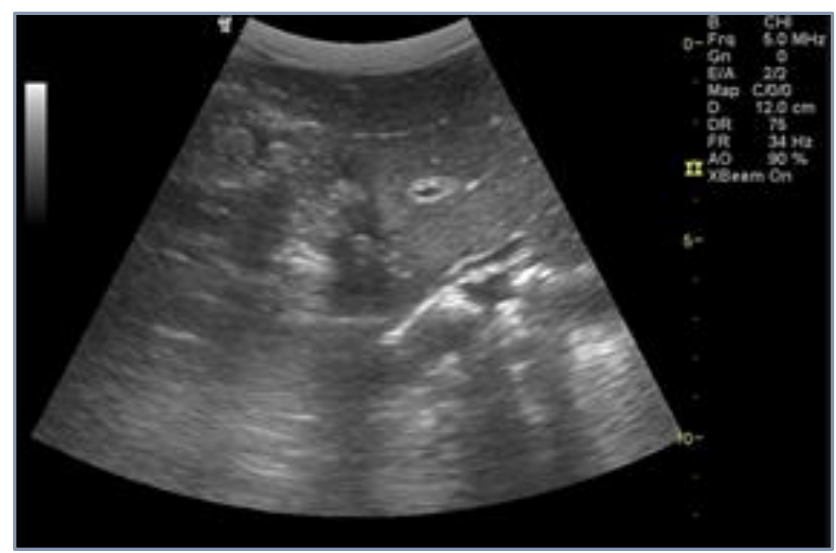

Fig.4

The USG (Fig. 1-4) findings-there is a large hypoechoic lesion with solid cystic lesion with fatty component and multiple calcific foci (Some of these calcifications on the longitudinal scans were suggestive of bones) seen between liver and rt. Kidney. The lesion is displaced kidney anteriorly in the lower pelvic (retroperitoneal lesion). Sonographic findings were nonspecific and further evaluation was advised with Multidetector Computed Tomography (MDCT) and Magnetic Resonance Imaging (MRI), possible diagnosis-a foetus in foetu or retroperitoneal teratoma.

\section{The CECT Abdomen IMAGES}

A contrast-enhanced (intravenous iodixanol) abdominal computed tomography (CT) examination is performed on a 16-row multidetector CT (GE).

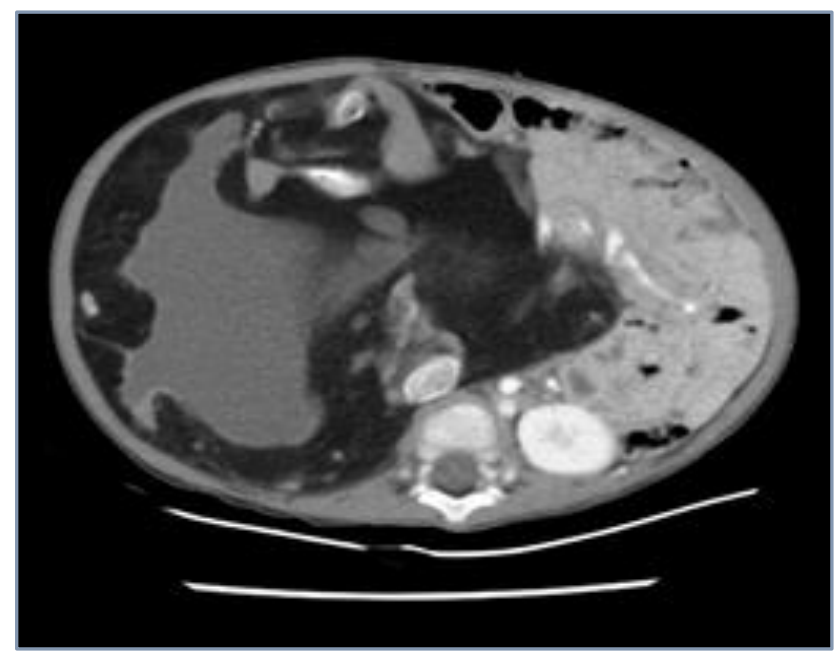

Fig. 5

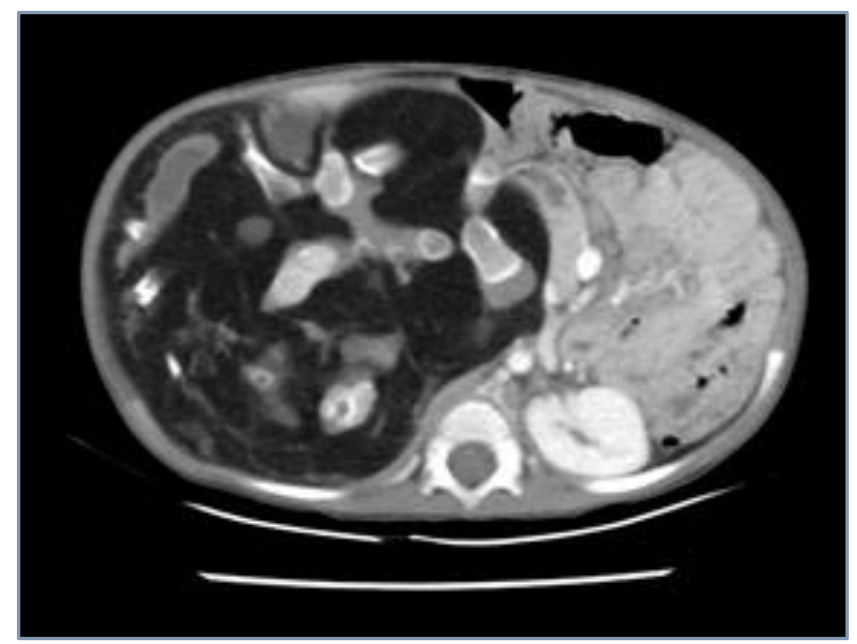

Fig. 6

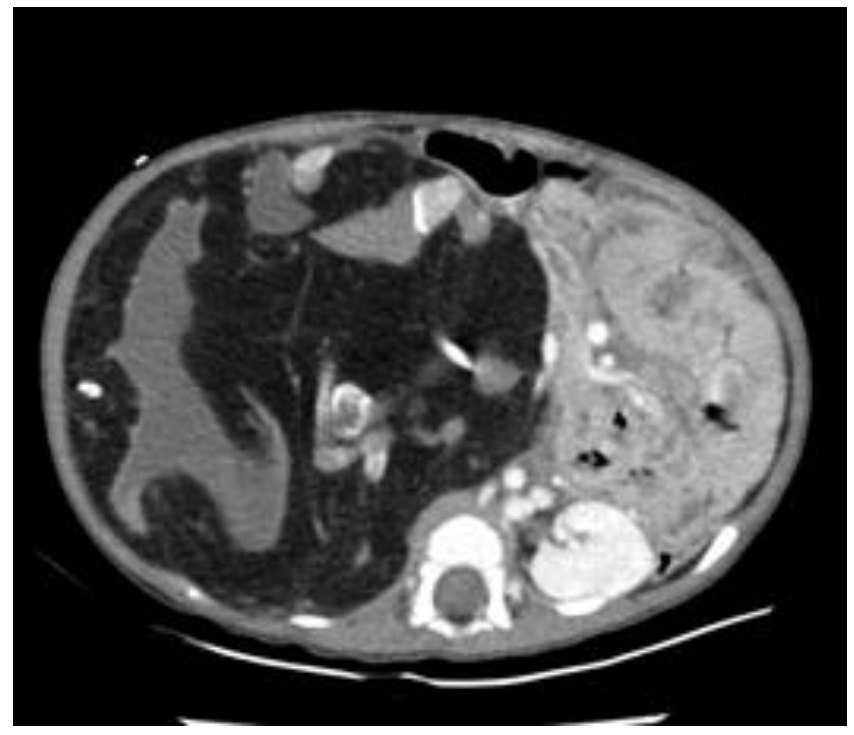

Fig. 7

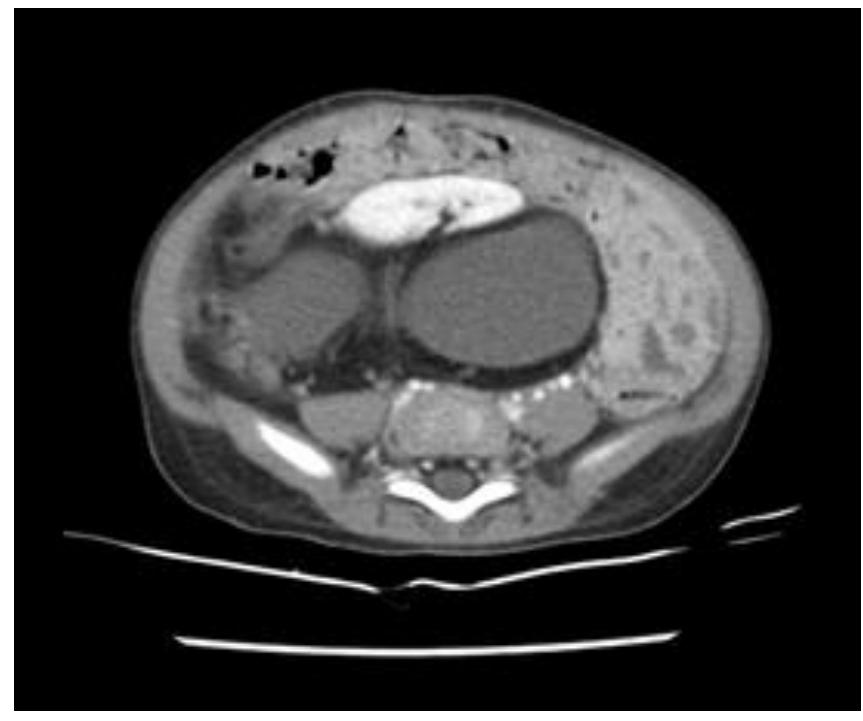

Fig.8 


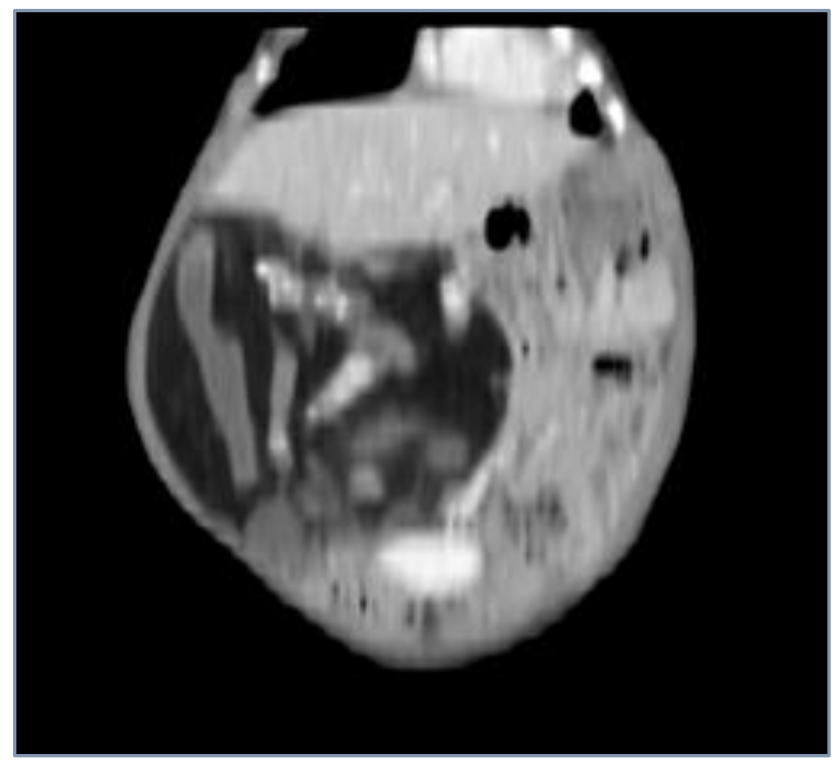

Fig. 9

The post-contrast CT images (Fig. 5-9) reveals a large retroperitoneal heterogeneous solid/cystic lesion of size $\left(15^{*} 15^{*} 25.6\right)$ between right kidney and liver; that has soft tissue, fat component, which surrounds the bone (The bony component resemble a vertebral body and long bone). The lesion is displacing the right kidney anteriorly in lower pelvis. The bowel loops are displaced in the left side of peritoneal cavity. The course of major abdominal vessels and right renal vessels are distorted.

Diagnosis-FIF (FOETUS IN FOETU).

\section{The Multiplanar MRI of Abdomen of the Child}

MRI of abdomen was done with 1.5T scanner(GE), The MRI protocol used an axial and coronal T2-weighted Half-Fourier Acquisition Single-Shot Turbo SE (HASTE) sequence, axial 2-D Fast Low Angle Shot (FLASH) plus fat suppression sequence, axial, sagittal, and coronal true fast sequence (TRUFI).

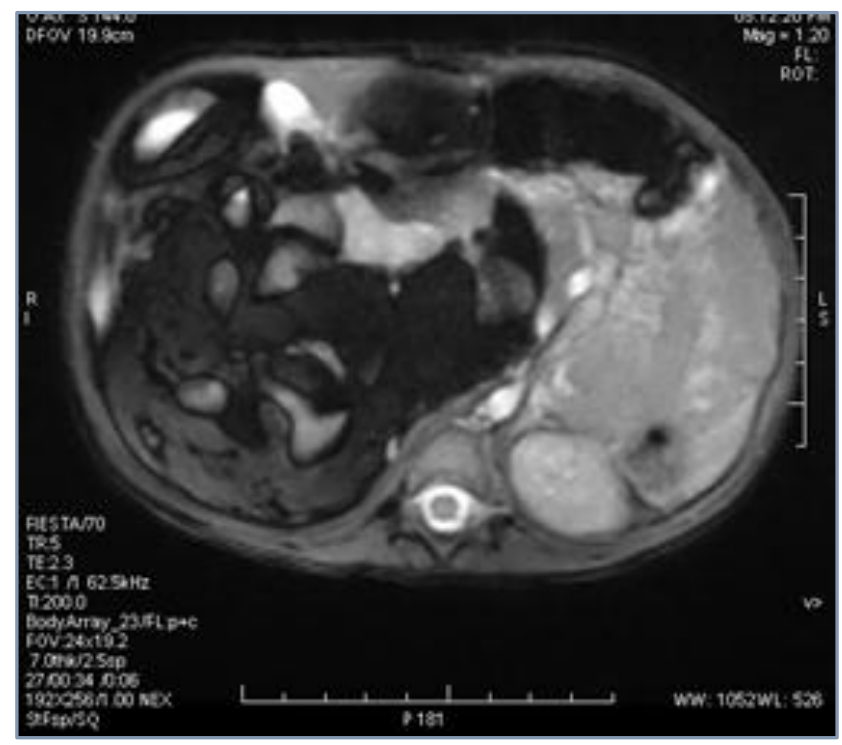

Fig.10

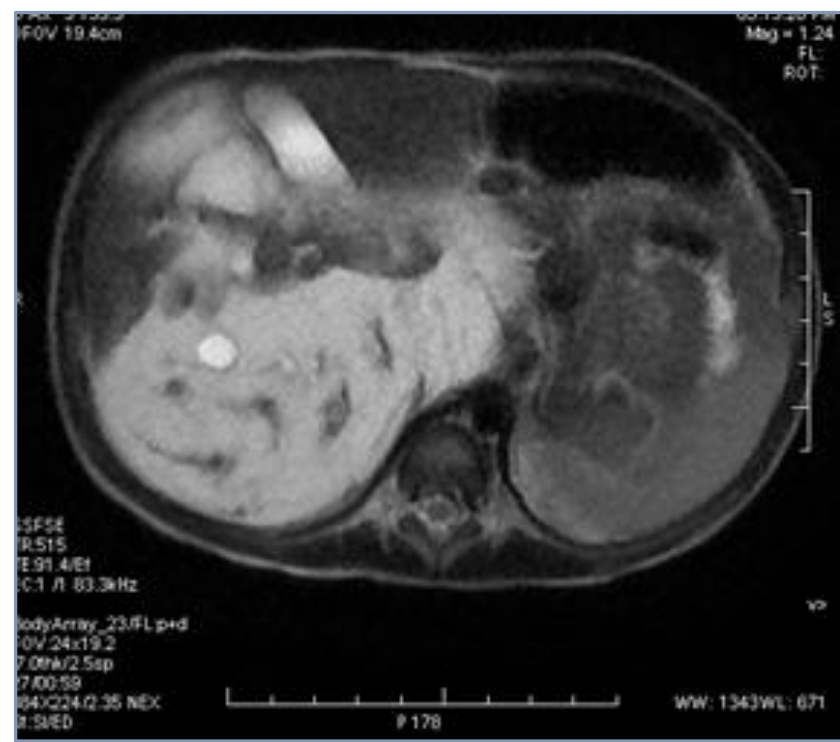

Fig.11

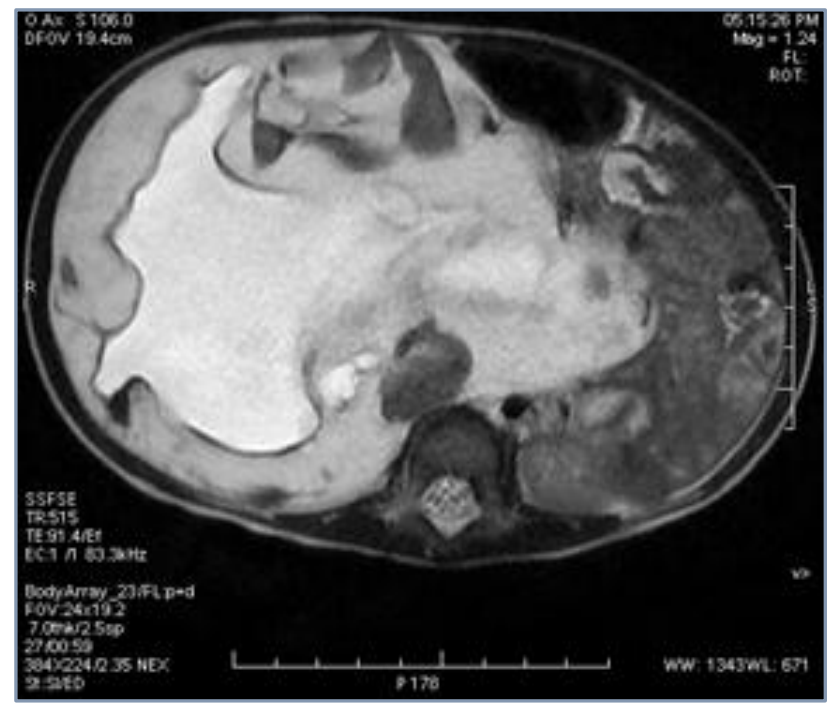

Fig.12

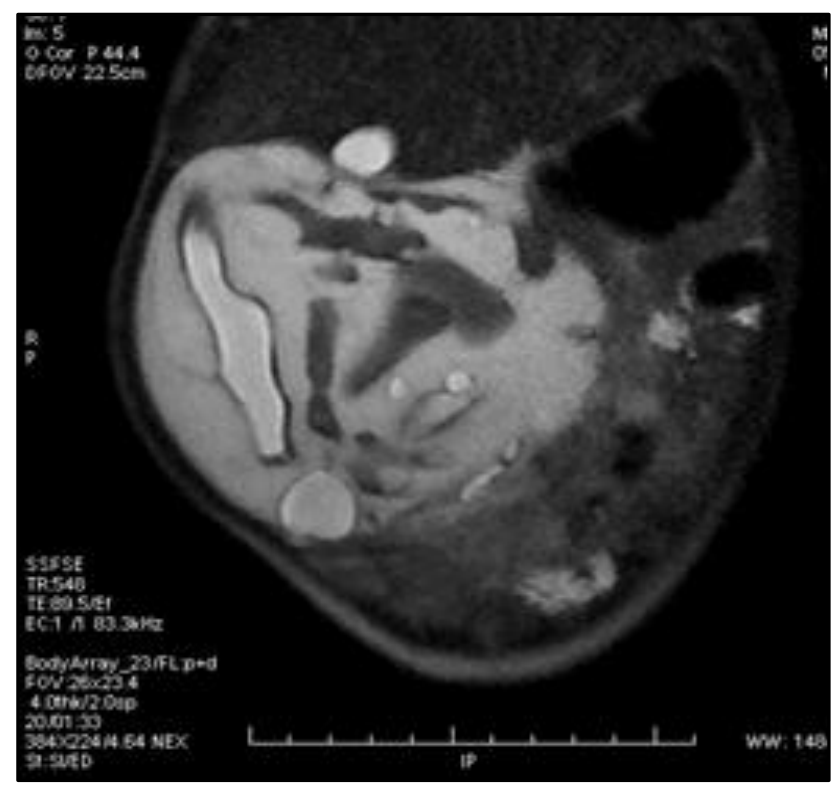

Fig.13 


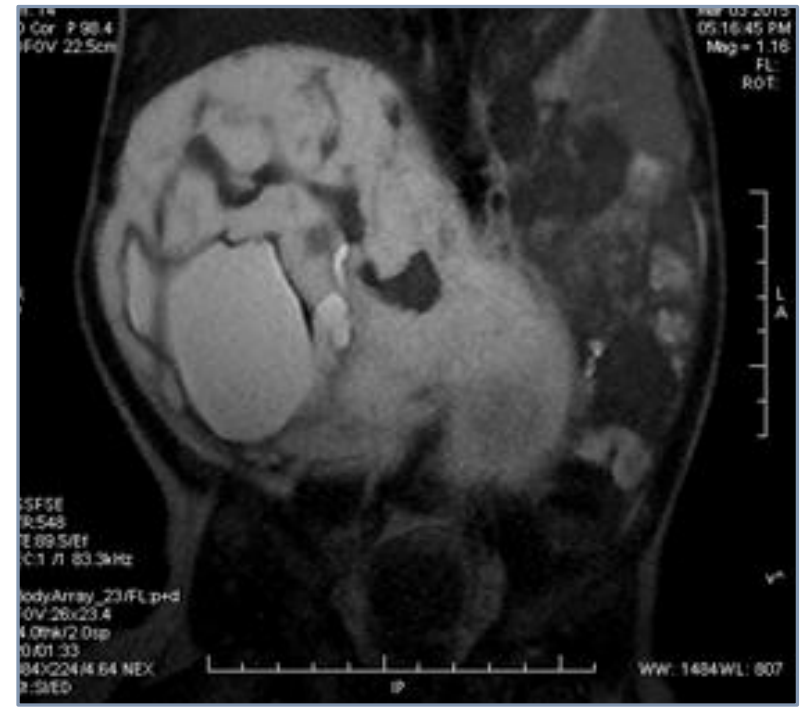

Fig.14

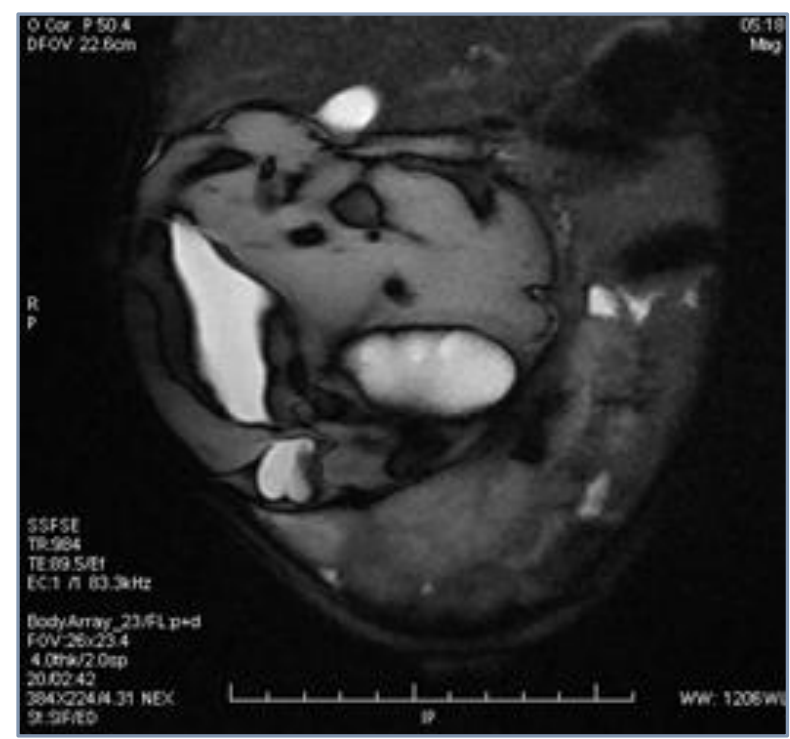

Fig.15

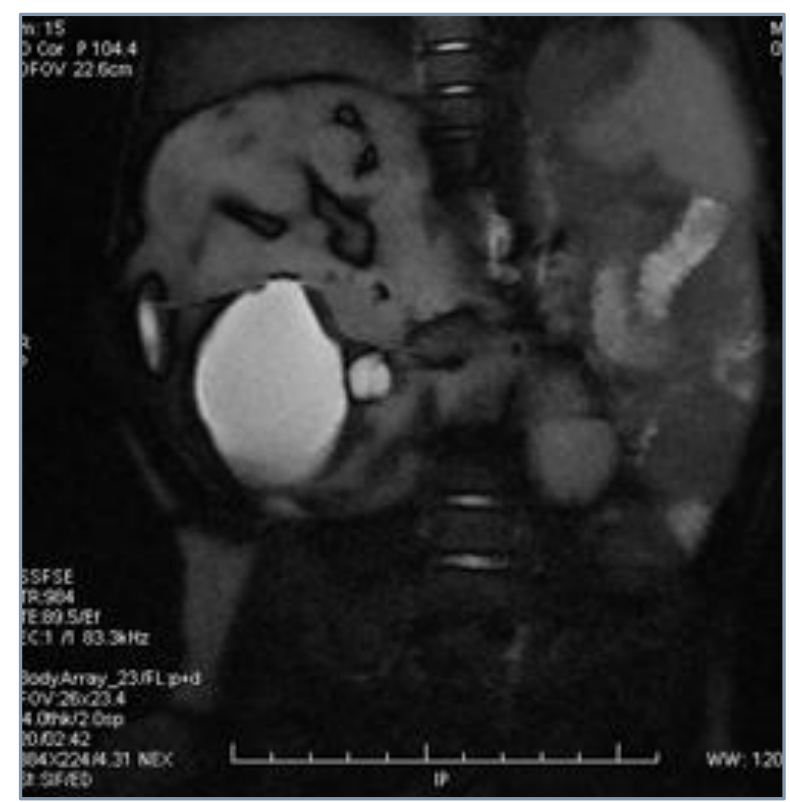

Fig.16

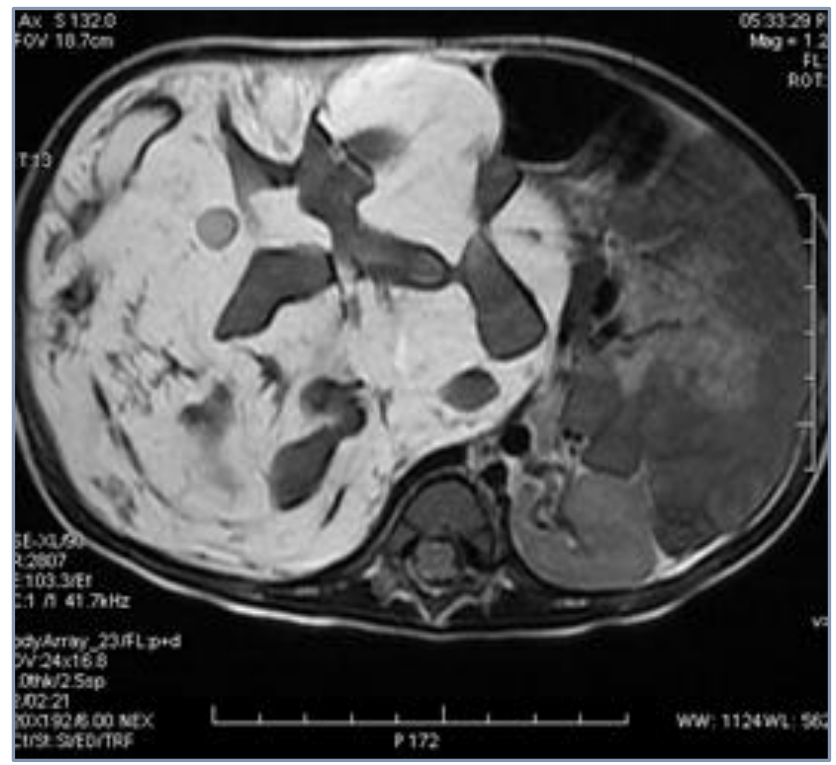

Fig.17

On MRI, CT findings were confirmed and mixed, high, intermediate, and low intensities were seen within the mass (Fig. 10-17). Bony structures seen within the miniature foetus were few irregular vertebral bodies, rib like bones, and long bone suggesting remnants of a second foetus. Facial and calvarial bones could not be seen.

\section{PATHOLOGY}

The exact embryogenesis of foetus-in-foetu is controversial there are two schools of thought:

- Some propose it occurs from the anomalous embryogenesis in a diamniotic monochorionic twin pregnancy in which a malformed monozygotic twin lies within the body of its fellow twin.

- Others consider it to represent a highly organised teratoma.

\section{DISCUSSION}

The foetus was always anencephalic. The vertebral column and the limbs were present in the foetus in foetu in almost all cases [ $91 \%$ and $82.5 \%$, respectively]. There is controversy as to whether foetus in foetu is a distinct entity or represents a highly-organised teratoma. A teratoma is defined as a neoplasm with a slight potential for malignancy that is composed of multiple tissues foreign to the part in which they are located.[2]

Foetus in foetu is thought to result from the unequal division of the totipotent inner cell mass of the developing blastocyst. This results in the inclusion of a small cell mass within a maturing sister embryo. The result is an included vestigial remnant of a diamniotic monochorionic twin that is located within the body of the otherwise normally developed twin.(7)

It often is difficult to make a distinction between teratomas and vestigial remnants that result from abortive attempts at twinning. As a result, some authors think that foetus in foetu is within the spectrum of abnormalities that can result from the anomalous embryogenesis in a diamniotic monochorionic pregnancy. The spectrum includes conjoined symmetric twins; 
parasitic foetuses; embryonic vestigial foetal inclusions; and organised teratoma.(2)

With the advances in ultrasonography, one can associate early diagnosis with improved patient outcomes.(8) However, ultrasound sometimes is not confirmatory and as discussed often leads to a wide differential diagnosis. With the increased use of CT and MRI, the capability of narrowing to a single diagnosis has greatly improved.(9) In today's technologically advanced world, prenatal diagnosis is on the rise. Diagnosis with US was first reported by Nicolini et al.(10)

\section{CONCLUSION}

Foetus-in-foetu (FIF) is a rarely diagnosed condition. FIF could be considered as a rare differential of teratoma in an infant or young child presenting with progressively increasing abdominal swelling and vomiting. Presence of axial skeleton distinguishes FIF from teratoma; however, it can be seen only in $91 \%$ of cases on imaging. Current imaging modalities (USG, MDCT, and MRI) findings may allow us to accurately diagnose the condition before surgery. Complete excision is curative and allows confirmation of the diagnosis.

\section{REFERENCES}

1. Luzzatto C, Talenti E, Tregnaghi A, et al. Double foetus in foetu: diagnostic imaging. Paediatr Radiol 1994; 24(8): 602-3.
2. Potter EL. Pathology of the foetus and the newborn. $2^{\text {nd }}$ ed. In: Potter EL, ed. Chicago III: Year Book 1961:183-7.

3. Yang ST, Leow SW. Intracranial foetus in foetu: CT diagnosis. AJNR Am J Neuroradiol 1992;13(5):1326-9.

4. Heifetz SA, Alrabeeah A, Brown BS, et al. Foetus in foetu: a foetiform teratoma. Paediatr Pathol 1988;8(2):215-26.

5. Federici S, Ceccarelli PL, Ferrari M, et al. Foetus in foetu: report of three cases and review of literature. Paediatr Surg Int 1991;6(1):60-5.

6. Carles D, Alberti EM, Serville F, et al. Foetus in foetu and acardiac monster: can the similar patterns of these two malformations be explained by a common morphological mechanism? Arch Anat Cytol Pathol 1991;39(3):77-82.

7. Willis RA. The borderland of embryology and pathology. $2^{\text {nd }}$ ed. Washington DC: Butterworth and Company 1962:442-62.

8. Hing A, Corteville J, Foglia RP, et al. Downton foetus in foetu: molecular analysis of a foetiform mass. Am J Med Genet 1993;47(3):333-41.

9. Patankar T, Fatterpekar GM, Prasad S, et al. Foetus in foetu: CT appearance-report of two cases. Radiology 2000;214(3):735-7.

10. Nicolini U, Dell'Agnola CA, Ferrazzi E, et al. Ultrasonic prenatal diagnosis of foetus in foetu. J Clin Ultrasound 1983;11(6):321-2. 